\title{
Device for Streptavidin Detection Using LSPR and Electrochemical Transductions on the same Platform
}

\author{
Maria G. V. Fressatti, ${ }^{a}$ Bento P. Cabral Jr., ${ }^{a}$ Jean H. de Oliveira, ${ }^{a}$ Paulo H. M. Buzzetti, ${ }^{\oplus a}$ \\ Eduardo Radovanovic, ${ }^{\circledR a}$ Johny P. Monteiro ${ }^{\circledR *, b}$ and Emerson M. Girotto ${ }^{\circledR *, a}$ \\ aLaboratório de Química de Materiais e Sensores (LMSEN), Departamento de Química, \\ Universidade Estadual de Maringá, Avenida Colombo, 5790, 87020-900 Maringá-PR, Brazil \\ ${ }^{b}$ Laboratório de Materiais, Macromoléculas e Compósitos (LaMMAC), Departamento de Química, \\ Universidade Tecnológica Federal do Paraná, Rua Marcílio Dias, 635, \\ 86812-460 Apucarana-PR, Brazil
}

\begin{abstract}
Research in biosensing currently occupies an important role among biomolecular detection techniques, especially with respect to medical diagnoses. Is this sense, the development of biosensors based on the localized surface plasmon resonance (an optical transducer) or electrochemical transductions have been highlighted. However, optical and electrochemical detection working together enable more versatile detections in biosensing. Thus, we propose a dual sensor, which incorporates these two mechanisms on the same platform. The sensor shared the same transducer that was based on a glass-indium thin oxide (ITO) surface covered with gold nanoparticles. The transducer was prepared by the immobilization of gold nanoparticles on (3-aminopropyl)triethoxysilane-activated glass-ITO. The substrate ability to respond to physical surface variations was assessed. For this, measurements of the gold nanoparticles band redshift (plasmonic transduction) and charge transfer resistance from impedance spectra (electrochemical transduction) were performed. The platform was able to detect streptavidin immobilized on the surface by both mechanisms demonstrating its applicability as a device for biodetection in dual detection mode.
\end{abstract}

Keywords: localized surface plasmon resonance, electrochemical impedance spectroscopy, dual transduction, gold nanoparticles, biosensor

\section{Introduction}

The need for improved medical and environmental analysis encourages new strategies to determine and quantify biospecies. Quick analysis, low cost, and smaller devices have been evidenced in the scientific research area. Biosensors meet these requirements ${ }^{1}$ and therefore have been widely used in different areas, such as analysis of food, ${ }^{2,3}$ in medical science, ${ }^{4-6}$ environmental science, ${ }^{7}$ and others. ${ }^{89}$ Basically, a biosensor has two main elements: a bioreceptor that recognizes specifically the target analyte, and a transductor that converts this interaction into a measurable signal. ${ }^{10,11}$ The nature of the transducers may be diverse, such as electrochemistry, optics, piezoelectric or thermal. ${ }^{12}$ However, electrochemical and optical transductions are usually more exploited in biosensors and some factors

*e-mail: johnypmonteiro@utfpr.edu.br; emgirotto@uem.br contribute to this fact: electrochemical technique is an older, well established and more studied technology and optical transductions stand out compared to other transducers types for their easy handling and minimized false responses. ${ }^{13,14}$

Optical transduction based on localized surface plasmon resonance (LSPR) is widely used to detect biochemical interactions due to its great performance. ${ }^{15,16} \mathrm{LSPR}$ is a phenomenon produced by the resonant interaction between an incident electromagnetic wave with electrons in metallic nanoparticles. ${ }^{17}$ This phenomenon is strongly dependent on the nanoparticles surrounding dielectric medium, which can be used, e.g., as a probe to monitor metallic surface functionalization. ${ }^{18,19}$ Noble metals such as $\mathrm{Au}, \mathrm{Ag}, \mathrm{Pd}$, and Pt can support surface plasmons. ${ }^{20-22}$ Copper has also been explored. ${ }^{23}$ However, Ag and Au exhibit a more intensified LSPR effect and are therefore normally employed..$^{20,21,24}$ Gold is usually the best choice for many applications as it exhibits greater inertia in the face of oxidative processes..$^{25}$ 
The electrochemical biosensors are summed up in four measuring techniques: potentiometric, amperometric, and conductometric/impedimetric. ${ }^{26}$ The amperometric method is characterized by the application of a potential to the working electrode versus the reference electrode, as a result, electric currents of redox reactions are observed due to electron transfer between the electroactive analyte and the electrode; these measurements are limited by mass transport from species to the electrode. The potentiometric method is characterized by verification of the electrochemical potential observed in the electrochemical cell, which may be further classified into three types, ion-selective electrodes (IES), coated wire electrodes (CWES) and fieldeffect transistors (FETS). ${ }^{27,28}$ Condutimetric/impedimetric method monitors the ability of an electroactive species to transfer electrons to the working electrode, normally under a modified electrode, such as the formation of non-conductive films. The electrochemical impedance spectroscopy (EIS) has been a good choice for biosensing applications. The EIS has some advantages as a transduction technique due to its fast detection of the target protein at the electrodesolution interface. ${ }^{5,29,30}$ Further, nanomaterials such as carbon nanotubes, ${ }^{31}$ magnetic nanoparticles, ${ }^{32}$ and metallic nanostructures ${ }^{33}$ can be used to produce electrochemical biosensors with improved properties due to the sizeenhanced characteristics. ${ }^{34}$

The transduction step can be improved by the use of a dual-type detection using different transducers, which results in a more reliable biosensor. The elaboration of a sensor with optical and electrochemical transductions can incorporate many advantages in the device such as broader dynamic range (dynamic ranges can be combined), to obtain more complete information from the sample, and responses self-validation. In addition, the individual characteristics of each detection mode are maintained. The LSPR sensors show detection free of molecule labeling, in vivo applications, suitable for multiplexing detection, and no influence of magnetic, and electric fields on the measurements. On the other hand, the electrochemical ones do not suffer influence from ambient light variation, there is no concern with chromophore photobleaching, and shows a greater dynamic range. ${ }^{35}$ The incorporation of two transduction mechanisms will make the device more versatile because the two techniques can complement each other. Thus, both transductions can be used to detect the same analyte to obtain more complete data or the technique more compatible with the analysis and sample conditions can be selected to guarantee more reliable answers.

The sensors development that combines optical and electrochemical transduction has been explored for at least a decade and has found interesting applications.
One of the first works found in the literature reports an amperometric and chemiluminescent sensor based on poly(methyl methacrylate)-coated optic fiber modified with poly(pyrrole-benzophenone). The device was used for detection of both urea and hydrogen peroxide using the same platform. ${ }^{36}$ In another similar work, ${ }^{37}$ an indium tin oxide (ITO)-coated optical fiber and also activated by poly(pyrrolebenzophenone) was used to immobilize and detect cholera toxin by optical (chemiluminescence) and electrochemical (amperometric) transductions. More recently, detection of avidin using a platform based on Au-coated silicon nanowires deposited on glass substrate has been shown. Surface enhanced Raman scattering (SERS) and EIS were both used for protein detection..$^{38}$ SERS has still been used in conjunction with voltammetric measurements to quantify the interaction between anti-cancer drugs and cancer cell deoxyribonucleic acid (DNA) fragment. ${ }^{39}$

SERS generated in nanostructures surfaces is extremely sensitive and enables substances detection at a single molecule level. However, this technique has some practical disadvantages such as the difficulty in interpreting spectra (Raman signals appear in SERS spectra and contaminants traces may contribute with peaks), relatively expensive equipment (Raman), and the Raman signal enhanced on the surface is quite critical and dependent on many aspects. Therefore, plasmonic techniques can be successfully applied in cases where an ultrasensitive analysis is not required. In this sense, a sensor that operates with EIS and the attenuated total reflectance effect (traditional Kretschmann plasmonic configuration) has been reported. Both techniques were used for clenbuterol dual detection using a graphene-coated gold surface as transducer. ${ }^{40}$ Lazar et al. ${ }^{41}$ showed the usage of gold-coated nanoporous polycarbonate membranes to also obtain a resourceful dual detection microfluidic device. Simultaneous signals of EIS and LSPR on the metallic nanoporous platform were evaluated in flow under various treatments performed on the membrane.

Gold nanoparticles (AuNPs) have been employed in the development of sensors that operate with optical and electrochemical transductions. AuNPs exhibit interesting optical properties (from the LSPR effect) that can be exploited. In addition, they are useful for improving the performance of electrodes in electrochemical measurements due to their good conductivity and high surface area by volume ratio. Cheng et al. ${ }^{42}$ reported a glass/ITO-based sensor covered with electrodeposited gold nanocolloids to detect DNA hybridization. A potentiostat was used to evaluate electrochemically (EIS) the glass/ITO/AuNPS surface. However, a complex light reflection system was used to evaluate the LSPR responses of the AuNPs during 
the transducer surface modifications. Comparatively, in other more recent work ${ }^{43}$ gold nanocups filled with AuNPs on glass substrate were used for dual detection of heavy metal ions. In this case, the optical evaluation of the LSPR effect was simpler and based on the light absorption. On the other hand, a less sensitive electrochemical technique (based on voltammetry) was employed.

Whereas the combination of two transduction methods in the same device becomes an interesting approach, we propose here the development of a simpler biosensing platform that explores the LSPR and EIS transduction techniques. The same transducer was shared by both detection methods and it was based on AuNPs coated-glass/ ITO substrate. The AuNPs were obtained by conventional chemical reduction and chemically adsorbed on aminated ITO surfaces. The nanoparticles morphology (size and shape) is better controlled by chemical synthesis than by electrodeposition. Furthermore, the LSPR measurements were performed in conventional absorption mode and the EIS ones were obtained by the common potentiostat. The transducer surface was functionalized with cysteamine and thiolated biotin to detect streptavidin using a label-free sensing mode.

\section{Experimental}

\section{Materials}

Tetrachloroauric acid $\left(\mathrm{HAuCl}_{4}\right.$, ca. $\left.30 \% \mathrm{~m} / \mathrm{v}\right)$, sodium citrate (99\%), (3-aminopropyl)triethoxysilane (APTES, 99\%), D-(+)-glucose (99.5\%), cysteamine (95\%), biotinsulfo-NHS (BNHS, 90\%), streptavidin $(65 \%)$, and the redox couple $\left[\mathrm{Fe}(\mathrm{CN})_{6}\right]^{3-14-}(99 \%)$ were purchased from Sigma-Aldrich, St. Louis, USA. The phosphate buffered saline (PBS) was obtained with $0.0820 \mathrm{~g} \mathrm{~mL}^{-1}$ NaCL (99.5\%, Sigma-Aldrich, St. Louis, USA), $0.0105 \mathrm{~g} \mathrm{~mL}^{-1} \mathrm{Na}_{2} \mathrm{HPO}_{4}$ (98\%, Anidrol, Diadema, Brazil) and $0.0355 \mathrm{~g} \mathrm{~mL}^{-1} \mathrm{NaH}_{2} \mathrm{PO}_{4}$ (98\%, Anidrol, Diadema, Brazil). Potassium chloride (99\%, Synth, Diadema, Brazil), ITO-coated glass slide $(1.0 \times 2.0 \times 0.1 \mathrm{~cm}$, resistance $7 \Omega \mathrm{sq}^{-1}$ ), and Milli-Q ${ }^{\circledR}$ (Maringá, Brazil) water were also used.

\section{Apparatus}

The optical performance was evaluated using absorption spectroscopy in the visible spectral region from 450 to $900 \mathrm{~nm}$ (USB2000+, Ocean Optics coupled with a tungsten light source). The morphological characterization of the nanoparticles was performed using transmission electron microscopy (TEM, Jeol, JEM 1400), and the average size calculated using the software Image-Pro Plus ${ }^{\circledast}$ v 4.5.0.29. ${ }^{44}$ The ITO/AuNPs substrates were evaluated by scanning electron microscopy (SEM, Quanta 250, FEI) and atomic force microscopy (AFM, Shimadzu, SPM-9700), using dynamic mode. The data were analyzed using Gwyddion software version $2.51 .{ }^{45}$ The electrochemical measurements were performed using an Autolab potentiostat/galvanostat (PGSTAT 302N, Metrohm) using a three-electrode cell with platinum sheet $\left(2.25 \mathrm{~cm}^{2}\right)$ as the counter-electrode, an $\mathrm{Ag} / \mathrm{AgCl}$ (saturated $\mathrm{KCl}$ ) as reference and ITO or ITO/AuNPs-coated glass slides as the working electrode $\left(0.51 \mathrm{~cm}^{2}\right)$.

\section{Gold nanoparticles synthesis}

The AuNPs were prepared using the Turkevich methodology. ${ }^{46}$ Briefly, in a three-necked bottle, $\mathrm{HAuCl}_{4}$ aqueous solution $\left(100 \mathrm{~mL}, 0.25 \mathrm{mmol} \mathrm{L}^{-1}\right)$ was stirred and heated to boil. Then, sodium citrate $(2.5 \mathrm{~mL}, 1 \% \mathrm{~m} / \mathrm{v})$ was added to the solution under vigorous stirring at $100{ }^{\circ} \mathrm{C}$. After $40 \mathrm{~min}$, the mixture was rapidly cooled in an icebath to stop the reaction. The suspension was stored in a refrigerator.

\section{Substrates preparation}

First, ITO/glass slides $(2.0 \times 1.0 \times 0.1 \mathrm{~cm})$ were cleaned in a water bath with soap, washed with deionized water and then ultrasonicated in Milli- ${ }^{\circledR}$ water, ethanol and acetone for 10 min each followed by drying in $\mathrm{N}_{2}$ (99.99\%, White Martins, Londrina, Brazil). The hydrophilization of the ITO surface was performed in a plasma cleaner (Harrick Plasma, PDC-002) for $60 \mathrm{~s}$. Subsequently, the substrates were immersed in an APTES ethanolic solution $(4 \% \mathrm{v} / \mathrm{v})$ at $50^{\circ} \mathrm{C}$ overnight followed by washing with ethanol, water and dried by $\mathrm{N}_{2}$ blow. Then, the substrates were left in an oven for $1 \mathrm{~h}$ at $100{ }^{\circ} \mathrm{C}$. Finally, they were cooled to room temperature and vertically immersed in AuNPs solution under stirring for $2 \mathrm{~h}$, washed with deionized water, and dried with $\mathrm{N}_{2}$ again.

The AuNPs deposition and electroactive surface area were evaluated by cyclic voltammetry using an electrochemical probe $\left(\left[\mathrm{Fe}(\mathrm{CN})_{6}\right]^{3-14-}, 5.0 \mathrm{mmol} \mathrm{L}^{-1}\right)$ with reversible reaction, and $0.5 \mathrm{~mol} \mathrm{~L}^{-1} \mathrm{KCl}$ in the range of -0.2 to $0.8 \mathrm{~V}$ and 10 to $150 \mathrm{mV} \mathrm{s}^{-1}$ (scan rate). The plasmonic sensitivity was studied by absorbance spectroscopy changing the surrounding medium of the AuNPs using glucose solutions. The plasmonic bulk sensitivity was obtained by the slope of the wavelength shift against the refractive index (RI) of the glucose solution. The RI of the glucose was measured using a portable refractometer (3850 PAL-RI, Atago). 


\section{Optical and electrochemical bioassay}

At first, ITO/AuNPs substrates were washed with deionized water and immersed in an aqueous solution of cysteamine $(50 \mu \mathrm{mol} \mathrm{L}-1)$ for $6 \mathrm{~h}$. Subsequently, the slides were washed in deionized water and immersed for $12 \mathrm{~h}$ in BNHS $\left(0.1 \mathrm{mg} \mathrm{mL}^{-1}\right)$. Finally, the substrates were immersed in a $0.5 \mathrm{mg} \mathrm{mL}^{-1} \mathrm{PBS}$ solution $(\mathrm{pH} 7.45)$ of streptavidin for $4 \mathrm{~h} .{ }^{47,48}$

The EIS was applied to determine the charge transfer resistance before and after the functionalization. The measurements were performed in PBS solution ( $\mathrm{pH} 7.45$ ) using the potential of $-100 \mathrm{mV}$, frequency range of $1 \mathrm{kHz}$ to $10 \mathrm{mHz}$, and $15 \mathrm{mV}$ of amplitude. The three-electrode electrochemical cell was thermostated at $25^{\circ} \mathrm{C}$ and was used ITO/AuNPs as the working electrode. Furthermore, using the same substrate rinsed lightly with PBS, the plasmonic band redshift was monitored after each functionalization step after the EIS measurement. For this, the ITO/AuNPs substrate was inserted into a cuvette and the LSPR spectra were evaluated in PBS solution using a spectrometer.

\section{Results and Discussion}

\section{Gold nanoparticles synthesis}

After the reaction, the solution showed a red-wine color indicating the AuNPs formation. Figure 1a shows the absorbance spectra of the solution with $\lambda_{\max }=506.1 \mathrm{~nm}$, which is related to LSPR of gold nanoparticles. ${ }^{49}$ The single absorption band with symmetric shape indicates a highly homogeneous synthesis of gold nanospheres, which can be proved with AuNPs images of TEM (Figure 1b). The narrow size distribution obtained in the histogram (Figure 1b inset) shows a good homogeneity with respect to the diameter.
The micrograph presented spherical nanoparticles with a calculated average diameter of $13.0 \pm 0.3 \mathrm{~nm}$.

\section{ITO/AuNPs substrates characterization}

Typical SEM images of the AuNPs assembled onto ITO substrates are displayed in Figure 2b. It is possible to notice a highly covered surface due to the strong interaction between the AuNPs and the aminated surface of the substrate, overlapping the AuNPs-AuNPs interactions. The substrate presented an absorption band with $\lambda_{\max }=533.5 \mathrm{~nm}$ as illustrated in Figure $2 \mathrm{a}$. A redshift of ca. $27 \mathrm{~nm}$ was observed in relation to the absorption maximum for the AuNPs suspension. This may be justified due to the significant decrease in interparticle distance during anchoring. It was also noticed that the AuNPs remained roughly spherical in shape. This is also supported because a single and well-defined plasmon band was still observed. In addition, the nanoparticles maintained good homogeneity of diameter distribution, since the full width at half maximum (FWHM) was of $88.9 \mathrm{~nm}$ that is close to the obtained AuNPs in suspension $(\mathrm{FWHM}=63.1 \mathrm{~nm})$. The agglomeration process caused the band broadening. ${ }^{50}$

\section{Evaluation of LSPR and electrochemical responses}

Figure 3 shows the visible absorption spectra of ITO/AuNPs in different glucose solutions. The plasmonic band presented a redshift as the refractive index increased as shown in the inset of Figure 3a. The sensitivity was obtained by the slope of $\lambda_{\max }$ versus glucose solutions RI (Figure 3b) curve. The ITO/AuNPs presented a sensitivity of $88.4 \mathrm{~nm} \mathrm{RIU}{ }^{-1}$, value comparable to that of self-assembled monolayers (SAMs) of gold nanoparticles
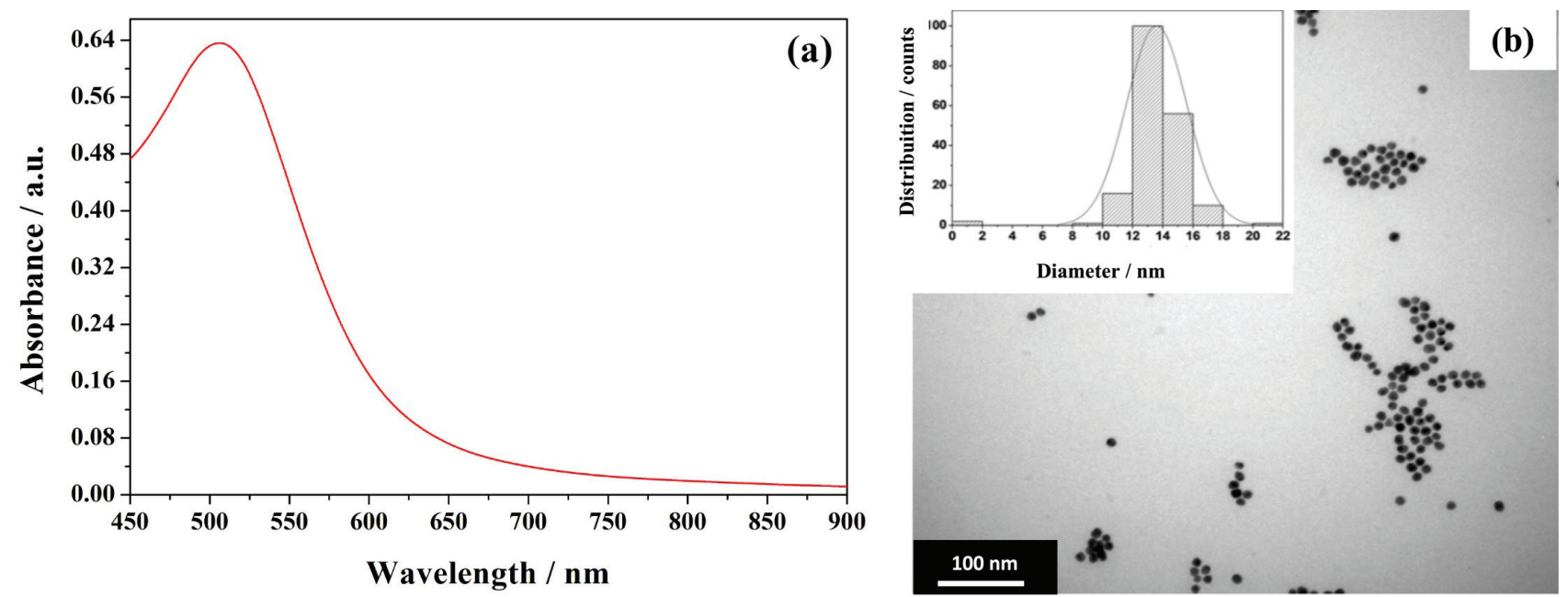

Figure 1. (a) Absorption spectra of AuNPs solution and (b) transmission electron microscopy image with a size distribution histogram. 

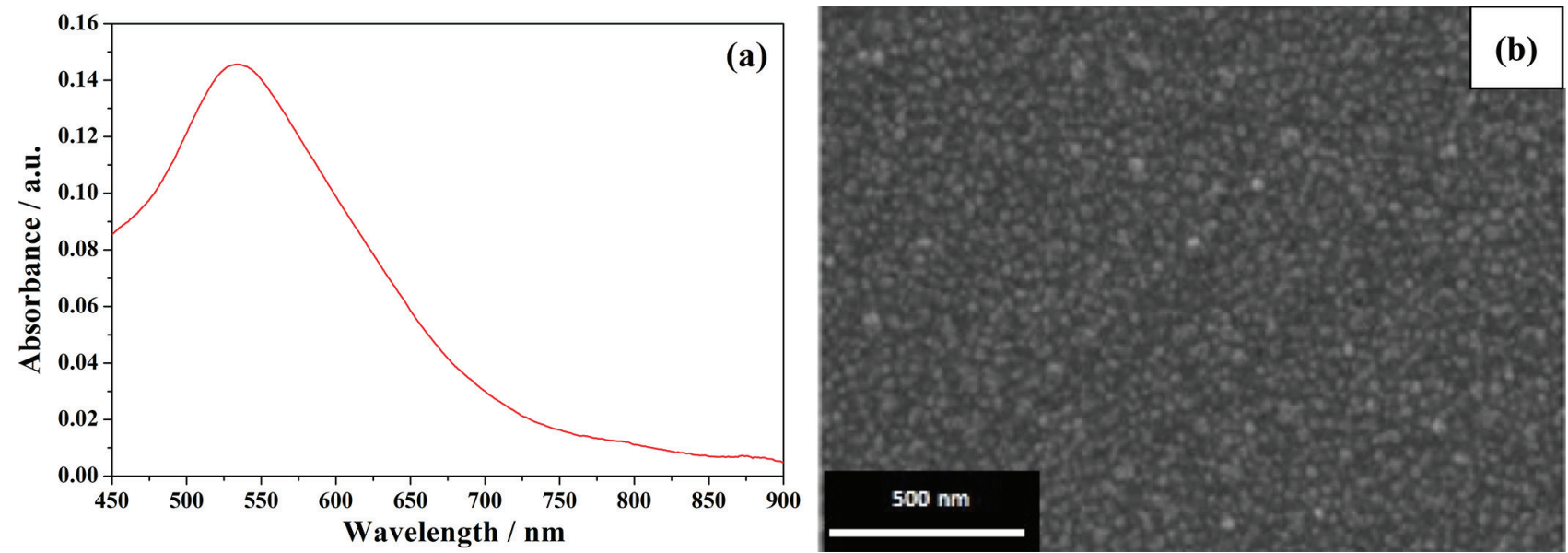

Figure 2. (a) Absorption spectrum and (b) scanning electron microscopy image of the AuNPs-coated glass-ITO substrates.
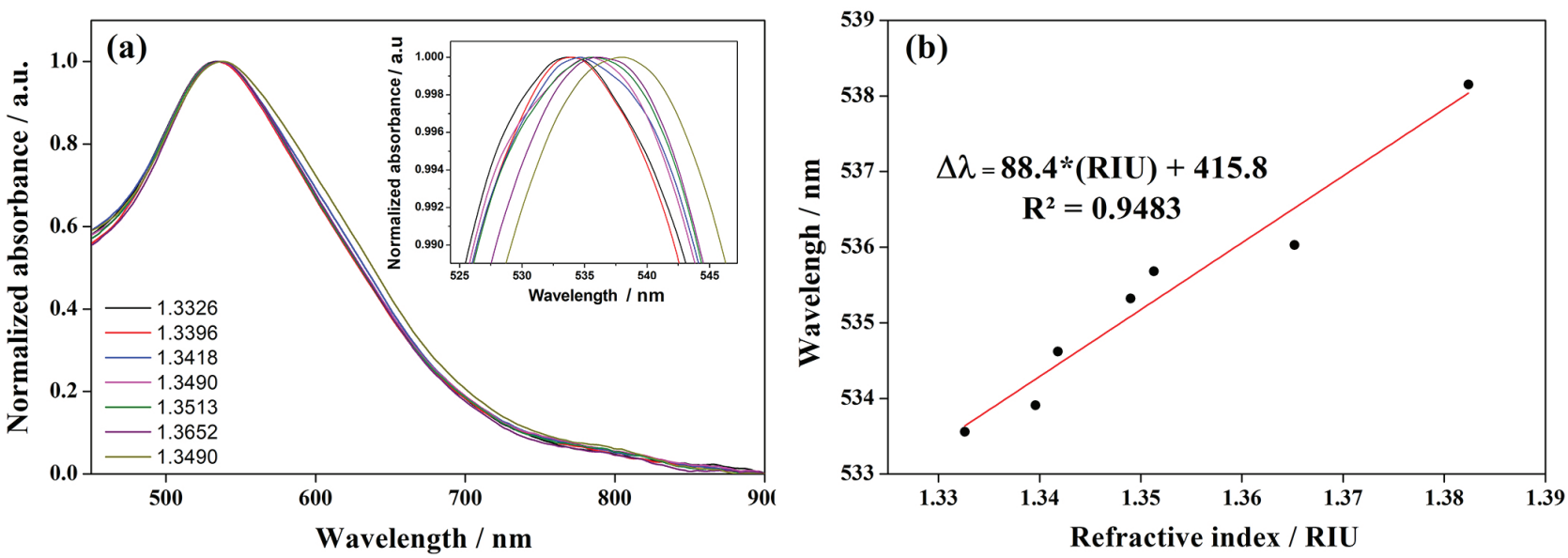

Figure 3. (a) Absorption spectra of glass-ITO/AuNPs substrate immersed in different glucose solutions with a closer view of the maximum absorption and (b) its linear fit with RI sensitivity of $88.4 \mathrm{~nm} \mathrm{RIU}{ }^{-1}$.

on silicon substrates. ${ }^{17,51}$ The bulk sensitivity is an important parameter, since it measures the plasmonic wave disturbance due to dielectric environment changes. ${ }^{17}$ This can be used to determine the substrate applicability in the monitoring of surface-anchored biomolecules. ${ }^{52,53}$ The sensitivity curves exhibited a coefficient of determination $\left(\mathrm{R}^{2}\right)$ close to 0.9483 , which represents that ca. $95 \%$ of the $\lambda_{\max }$ shift is explained by the correlation. A linear behavior is usually sought because the disturbances in plasmonic wave are integrally converted in outputs signals in this fitting type.

The electrochemical test indicated an increase in the electroactive surface area and conductivity when the AuNPs were anchored onto the glass-ITO. ${ }^{54,55}$ Figure 4 shows the voltammograms of glass-ITO and glass-ITO/AuNPs substrates in different scanning rates. The Randles Sevick equation ${ }^{56}$ has been used to calculate the electroactive area from the voltammograms results. Using this equation for the glass-ITO and glass-ITO/AuNPs linear curves (insets in Figures $4 \mathrm{a}$ and $4 \mathrm{~b}$ ), it was calculated an electroactive area of $0.81 \pm 0.04$ and $0.89 \pm 0.08 \mathrm{~cm}^{2}$, respectively. Based on these results, the glass-ITO/AuNPs presented an average electroactive area $17.7 \%$ higher than glass-ITO. This shows that the active regions of the electrode were enhanced mainly because of the roughness and conductivity enhance. The AFM topographical analysis of glass-ITO and glass-ITO/AuNPs are shown in Figure 5, respectively. The difference between topographies is clear. The AuNPs presence is noticed because the surface roughness shows a more symmetrical and more uniform distribution. Furthermore, the maximum $\mathrm{Z}$ range of the treated images shows a maximum height of $41.9 \mathrm{~nm}$ with AuNPs, which is $11 \mathrm{~nm}$ higher than pure ITO. The height increasing is close to the average radius for nanoparticles in aqueous suspension $(13 \mathrm{~nm})$. The analysis by Gwyddion presented a root mean square roughness (RMS) of $3.70 \mathrm{~nm}$ to glass-ITO and $4.35 \mathrm{~nm}$ to glass-ITO/AuNPs. The RMS ratio presented an increase of $17 \%$ due to the anchoring of AuNPs on ITO surface. ${ }^{57,58} \mathrm{In}$ fact, this increase is probably confirming the enhancement of the electroactive area. 

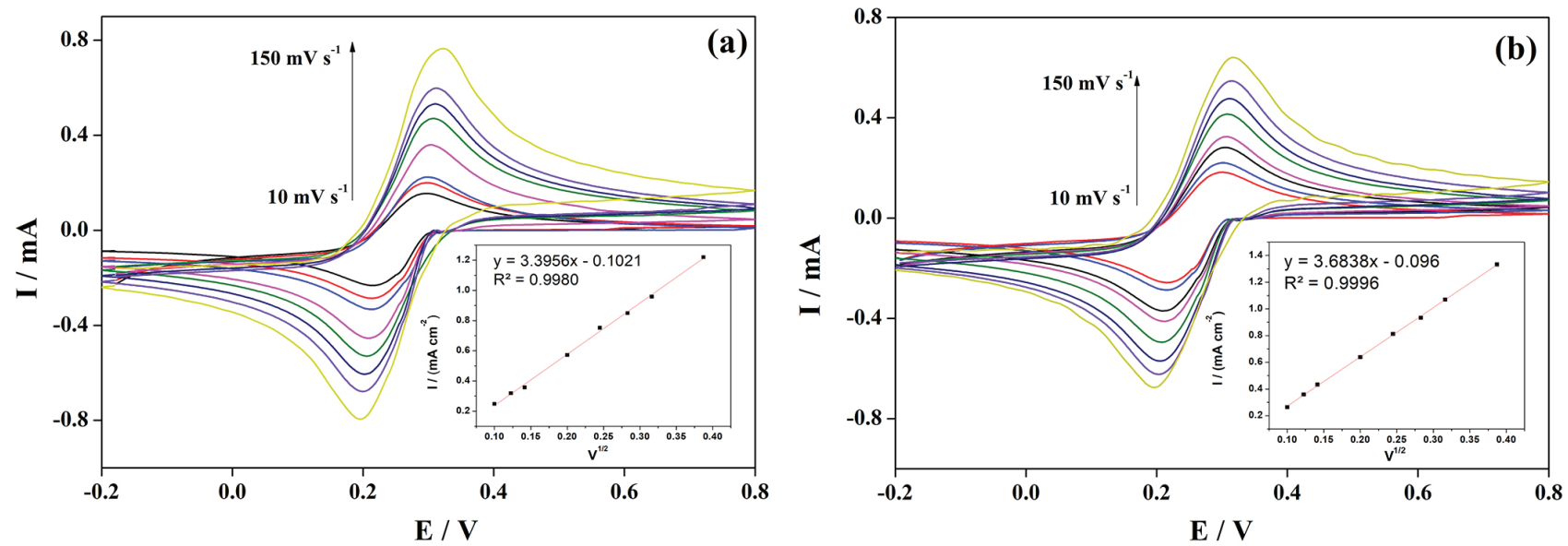

Figure 4. Cyclic voltammograms of $\mathrm{K}_{3}\left[\mathrm{Fe}(\mathrm{CN})_{6}\right]\left(5.0 \mathrm{mmol} \mathrm{L}^{-1}\right)$ in $\mathrm{KCl}\left(0.5 \mathrm{~mol} \mathrm{~L}^{-1}\right)$ to the (a) glass-ITO and (b) glass-ITO/AuNPs substrates. Scanning rates were from 10 to $150 \mathrm{mV} \mathrm{s}^{-1}\left(25^{\circ} \mathrm{C}\right)$ and the anodic peak at $380 \mathrm{mV}$ was evaluated. Insets show the current of the anodic peak versus square root of the scan rate.
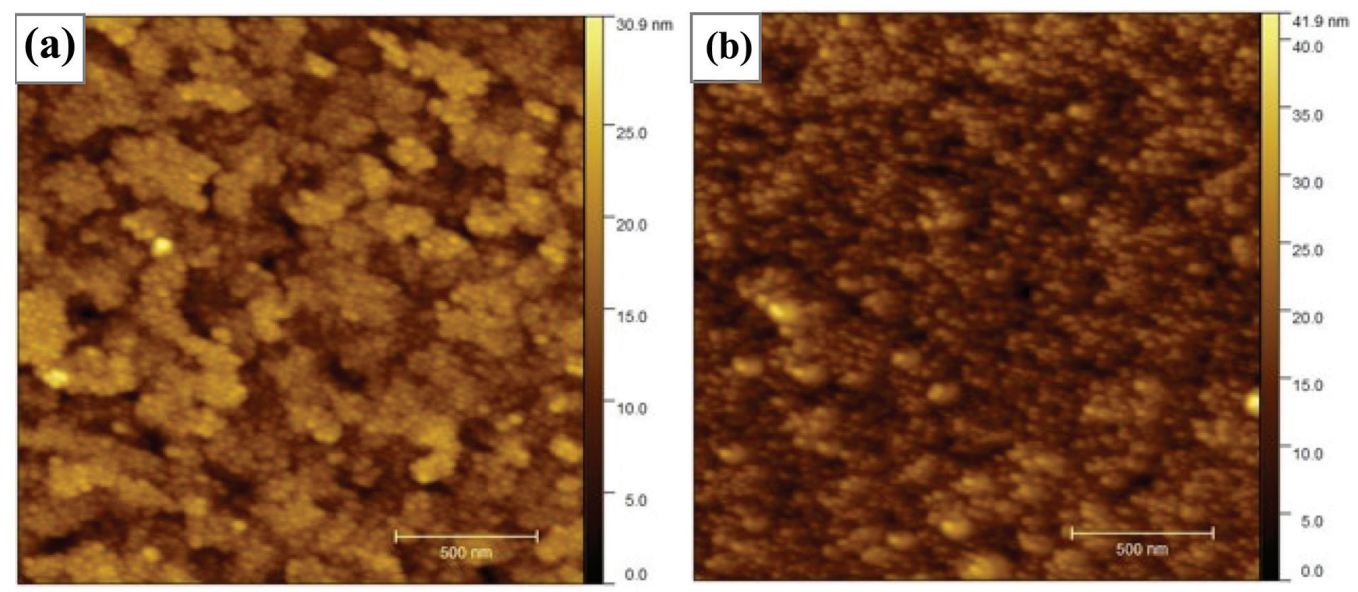

Figure 5. Atomic force microscopy images for the (a) glass-ITO and (b) glass-ITO/AuNPs substrates.

\section{Bioassay of streptavidin dual detection}

The first step to the biofunctionalization was to prepare a cysteamine layer on the AuNPs, as a result of the strong interaction between the Au surface and thiol groups of the cysteamine ensuring aminated nanoparticles. ${ }^{59}$ Secondly, the BNHS molecule bonds in the cysteamine $-\mathrm{NH}_{2}$ group by the removal of $N$-hydroxysuccinimide group. Then, it was possible to detect the streptavidin using the glass-ITO/AuNPs substrate due to the huge host-guest interaction with biotin (affinity constant $\left(\mathrm{K}_{\mathrm{a}}\right)$ ca. $\left.10^{15} \mathrm{~mol} \mathrm{~L}^{-1}\right) \cdot{ }^{60,61}$

The plasmonic wave disturb due to the functionalization on AuNPs allowed to monitor the streptavidin presence by the LSPR band redshifts (Figure 6a). ${ }^{62}$ The average $\lambda_{\max }$ (Figure 6a) after each modification was expressed in a bar chart, Figure $6 \mathrm{~b}$. The measures were performed in triplicate. The redshift caused by streptavidin was $4.2 \pm 0.2$ in relation to the biotin-covered AuNPs $\lambda_{\max }$. The higher disturbed in the plasmonic band for streptavidin molecules occurred because its show higher molecular weight (protein). ${ }^{53}$

Regarding the electrochemical transduction, it should be emphasized that the non-conductive species adsorption in working electrodes surfaces makes it less conductive and makes the redox process difficult. EIS technique can monitor these events using an electrochemical probe. ${ }^{5} \mathrm{At}$ $-100 \mathrm{mV}$, the dissolved $\mathrm{O}_{2}$ is involved in redox reactions and can be used as a probe to evaluate the decrease in conductivity of the electrode. Basically, EIS describe the system response due to a sinusoidal oscillation in the potential. The signal is measured by the impedance spectra, usually Nyquist graphs, where the semicircle diameter indicates the charge transfer resistance $\left(\mathrm{R}_{\mathrm{ct}}\right)$. This parameter is a quantitative response that measures the capacity of an electroactive specie $\left(\mathrm{O}_{2}\right.$ in this case) to share electrons on the electrode surface. ${ }^{42,63}$

Figure 7 a shows the Nyquist diagram for the electrodes under each modification step (AuNPs, cysteamine, biotin, 

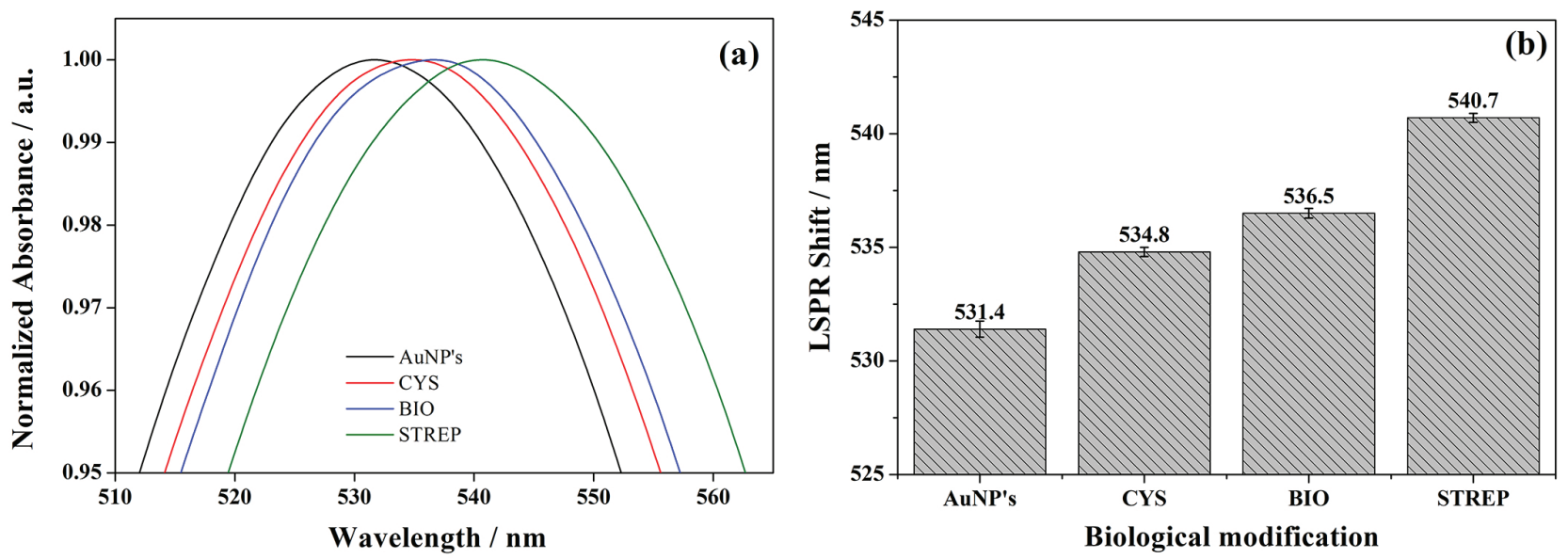

Figure 6. (a) Absorption spectra and (b) average $\lambda_{\max }$ for each functionalization steps of the biotest assay.
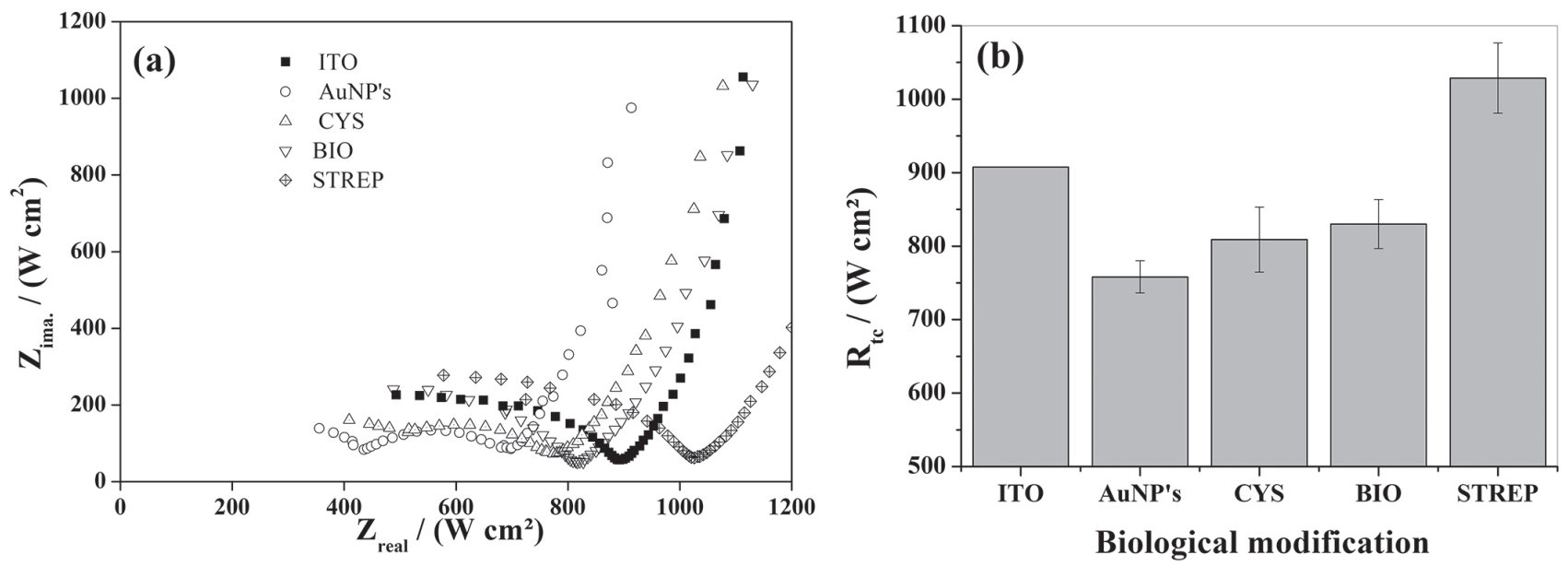

Figure 7. (a) Nyquist diagram in PBS ( $\mathrm{pH}=7.45$ ) and (b) bar graph to charge transfer resistance for each working electrode functionalization steps. Amplitude used was $15 \mathrm{mV}$ and frequency range was between $1 \mathrm{kHz}$ and $10 \mathrm{mHz}$ at $-100 \mathrm{mV}$.

streptavidin). The $\mathrm{R}_{\mathrm{ct}}$ values are given in graph bars (Figure 7b). Glass-ITO presented a $\mathrm{R}_{\mathrm{ct}}$ of $907.7 \Omega \mathrm{cm}^{-2}$ while glass-ITO/AuNPs gave a $758.2 \Omega \mathrm{cm}^{-2}$ resistance. The presence of AuNPs enhanced the conductivity at the electrodes surface and provided a larger electroactive area. The cysteamine layer raised the $\mathrm{R}_{\mathrm{ct}}$ to $809.1 \Omega \mathrm{cm}^{-2}$ due to the steric hindrance caused by the compact nonconductive layer. ${ }^{54,64}$ The posterior incorporation of biotin and streptavidin layer resulted in higher $\mathrm{R}_{\mathrm{ct}}$ values of 830.1 and $1028.8 \Omega \mathrm{cm}^{-2}$, respectively. The higher $\mathrm{R}_{\mathrm{ct}}$ obtained by streptavidin is related to the high-volume non-conductive protein making the charge transfer more difficult. ${ }^{65,66}$ It was also clear the possibility of detecting streptavidin molecules by the increase in the $\mathrm{R}_{\mathrm{ct}}$.

\section{Conclusions}

The AuNPs were morphologically and spectroscopically characterized and prepared as a self-assembled monolayer on glass-ITO. The substrate glass-ITO had a plasmonic sensitivity of $88.4 \mathrm{~nm} \mathrm{RIU}^{-1}$, which shows that the substrate was able for LSPR transduction. Furthermore, the assembly of AuNPs monolayer on glass-ITO promoted the desired increase in the electroactive area of the substrate. The dual detection method presented a reliable detection of the streptavidin using a few steps functionalization onto gold nanoparticles. A redshift of ca. $4 \mathrm{~nm}$ in the LSPR band and an increase of ca. $200 \Omega \mathrm{cm}^{-2}$ in the $\mathrm{R}_{\mathrm{ct}}$ were observed when streptavidin molecules were assembled on biotin monolayer. Both transduction techniques were able to monitor streptavidin using a shared transducer based on glass-ITO/AuNPs. It should also be noted that this device can provide real-time optical transduction, which is an interesting feature for the biosensing area.

\section{Acknowledgments}

We thank the Microscopy Central Complex Research Support (COMCAP) of the State University of Maringá (UEM)-Brazil for equipment support and Brazilian 
Agency CAPES for the financial support. This work was also supported by CNPq (Brazil) through Inomat-INCT, National Institute for Complex Functional Materials (CNPq $573644 / 2008-0)$

\section{Author Contributions}

Maria G. V. Fressatti led the problem investigation, methodology, and formal analysis; Bento P. Cabral Jr. helped in the problem investigation, methodology, and formal analysis; Jean $\mathrm{H}$. de Oliveira helped formal analysis and writing-review and editing; Paulo H. M. Buzzetti helped in the investigation, formal analysis, and writing-review and editing; Eduardo Radovanovic helped in the project administration, supervision, and writing-review and editing; Johny P. Monteiro helped in the project administration, supervision, visualization and led the writing-original draft, writing-review and editing; Emerson M. Girotto leads the funding acquisition, project administration, supervision, writing-original draft, and writing-review and editing.

\section{References}

1. Liu, D.; Luo, Q.; Deng, F.; Li, Z.; Li, B.; Shen, Z.; Anal. Chim. Acta 2017, 971, 26.

2. Ashley, J.; Li, S. F. Y.; Biosens. Bioelectron. 2013, 48, 126.

3. López, M. S.-P.; Redondo-Gómez, E.; López-Ruiz, B.; Talanta 2017, 175, 209.

4. Ertürk, G.; Özen, H.; Tümer, M. A.; Mattiasson, B.; Denizli, A.; Sens. Actuators, B 2016, 224, 823.

5. Wang, B.; Jing, R.; Qi, H.; Gao, Q.; Zhang, C.; J. Electroanal. Chem. 2016, 781, 212.

6. Tepeli, Y.; Ülkü, A.; Sens. Actuators, B 2018, 254, 377.

7. Dali, M.; Zinoubi, K.; Chrouda, A.; Abderrahmane, S.; Cherrad, S.; Jaffrezic-Renault, N.; J. Electroanal. Chem. 2018, 813, 9.

8. Faridbod, F.; Gupta, V. K.; Zamani, H. A.; Int. J. Electrochem. 2011, 2011, 352546.

9. Zeng, Y.; Zhu, Z.; Du, D.; Lin, Y.; J. Electroanal. Chem. 2016 , $781,147$.

10. Sassolas, A.; Blum, L. J.; Leca-Bouvier, B. D.; Biotechnol. Adv. 2012, 30, 489.

11. Singh, A.; Thapa, K. B.; Kumar, N.; Optik 2015, 126, 244.

12. Mehrotra, P.; J. Oral Biol. Craniofacial Res. 2016, 6, 153.

13. Braga, J. R. G.; Queiroz, A. A. A.; Ramos, A. C. B.; Int. J. Comput. Digital Syst. 2012, 1, 1 .

14. Senay, R. H.; Ulucan, F.; Kuru, C. İ.; Akgöl, S. In Smart Biosensing Technologies: Past, Present and Future; Gürsan, A. E.; Sezgintürk, M. K., eds.; Hacettepe Üniversitesi: Ankara, Turkey, 2018, p. 25-69.

15. Fan, X.; White, I. M.; Shopova, S. I.; Zhu, H.; Suter, J. D.; Sun, Y.; Anal. Chim. Acta 2008, 620,8.
16. Al-Ogaidi, I.; Gou, H.; Al-kazaz, A. K. A.; Aguilar, Z. P.; Melconian, A. K.; Zheng, P.; Wu, N.; Anal. Chim. Acta 2014, 811,76 .

17. Mayer, K. M.; Hafner, J. H.; Chem. Rev. 2011, 111, 3828.

18. Barnes, W. L.; Dereux, A.; Ebbesen, T. W.; Nature 2003, 424, 824.

19. Anker, J. N.; Hall, W. P.; Lyandres, O.; Shah, N. C.; Zhao, J.; van Duyne, R. P.; Nat. Mater. 2008, 7, 442.

20. Sugawa, K.; Tahara, H.; Yamashita, A.; Otsuki, J.; Sagara, T.; Harumoto, T.; Yanagida, S.; ACS Nano 2015, 9, 1895.

21. Zhang, N.; Han, C.; Xu, Y. J.; Foley, J. J.; Zhang, D.; Codrington, J.; Gray, S. K.; Sun, Y.; Nat. Photonics 2016, 10, 473.

22. Rycenga, M.; Cobley, C. M.; Zeng, J.; Li, W.; Moran, C. H.; Zhang, Q.; Qin, D.; Xia, Y.; Chem. Rev. 2011, 111, 3669.

23. Liu, P.; Wang, H.; Li, X.; Rui, M.; Zeng, H.; RSC Adv. 2015, 5,79738

24. Kunwar, S.; Sui, M.; Pandey, P.; Gu, Z.; Pandit, S.; Lee, J.; Sci. Rep. 2019, 9, 1329.

25. Santos, J. F. L.; Santos, M. J. L.; Thesing, A.; Tavares, F.; Griep, J.; Rodrigues, M. R. F. R.; Quim. Nova 2016, 39, 1098

26. Queirós, R. B.; Noronha, J. P.; Marques, P. V. S.; Sales, M. G. F.; Procedia Eng. 2012, 47, 758.

27. Stradiotto, N. R.; Yamanaka, H.; Zanoni, M. V. B.; J. Braz. Chem. Soc. 2003, 14, 159.

28. Ronkainen, N. J.; Halsall, H. B.; Heineman, W. R.; Chem. Soc. Rev. 2010, 39, 1747.

29. Daniels, J. S.; Pourmand, N.; Electroanalysis 2007, 19, 1239.

30. Qi, H.; Shangguan, L.; Li, C.; Li, X.; Gao, Q.; Zhang, C.; Biosens. Bioelectron. 2013, 39, 324.

31. Gupta, S.; Murthy, C. N.; Prabha, C. R.; Int. J. Biol. Macromol. 2018, 108, 687.

32. Freitas, M.; Viswanathan, S.; Nouws, H. P. A.; Oliveira, M. B. P. P.; Delerue-Matos, C.; Biosens. Bioelectron. 2014, 51, 195.

33. Xia, N.; Wang, X.; Yu, J.; Wu, Y.; Cheng, S.; Xing, Y.; Liu, L.; Sens. Actuators, B 2017, 239, 834.

34. Tian, L.; Qian, K.; Qi, J.; Liu, Q.; Yao, C.; Song, W.; Wang, Y.; Biosens. Bioelectron. 2018, 99, 564.

35. Eltzov, E.; Cosnier, S.; Marks, R. S.; Expert Rev. Mol. Diagn. 2011, 11, 533 .

36. Atias, D.; Abu-Rabeah, K.; Herrmann, S.; Frenkel, J.; Tavor, D.; Cosnier, S.; Marks, R. S.; Biosens. Bioelectron. 2009, 24 , 3683.

37. Konry, T.; Heyman, Y.; Cosnier, S.; Gorgy, K.; Marks, R. S.; Electrochim. Acta 2008, 53, 5128.

38. Convertino, A.; Mussi, V.; Maiolo, L.; Sci. Rep. 2016, 6, 25099.

39. Ilkhani, H.; Hughes, T.; Li, J.; Zhong, C. J.; Hepel, M.; Biosens. Bioelectron. 2016, 80, 257.

40. Yan, F.; Zhang, Y.; Zhang, S.; Zhao, J.; Liu, S.; He, L.; Feng, X.; Zhang, H.; Zhang, Z.; Microchim. Acta 2015, 182, 855.

41. Lazar, J.; Rosencrantz, R. R.; Elling, L.; Schnakenberg, U.; Anal. Chem. 2016, 88, 9590. 
42. Cheng, X. R.; Hau, B. Y. H.; Endo, T.; Kerman, K.; Biosens. Bioelectron. 2014, 53, 513.

43. Li, N.; Zhang, D.; Zhang, Q.; Lu, Y.; Jiang, J.; Liu, G. L.; Liu, Q.; Sens. Actuators, B 2016, 231, 349.

44. Image-Pro Plus, v. 4.5.0.29; Media Cybernetics, Silver Spring, USA, 2002.

45. Necas, D.; Klapetek, P.; Cent. Eur. J. Phys. 2012, 10, 181.

46. Turkevich, J.; Stevenson, P. C.; Hillier, J.; Discuss. Faraday Soc. 1951, 11, 55.

47. Monteiro, J. P.; de Oliveira, J. H.; Radovanovic, E.; Brolo, A. G.; Girotto, E. M.; Plasmonics 2016, 11, 45.

48. Cabral Jr., B. P.; de Oliveira, J. H.; Buzzetti, P. H. M.; Fressatti, M. G. V.; Monteiro, J. P.; Amorin, L. H. C.; Urbano, A.; Radovanovic, E.; Girotto, E. M.; Mater. Lett. 2018, 227, 243.

49. Ding, L.; Gao, Y.; Di, J.; Biosens. Bioelectron. 2016, 83, 9.

50. Chen, K. J.; Lu, C. J.; Talanta 2010, 81, 1670.

51. Chen, H.; Kou, X.; Yang, Z.; Ni, W.; Wang, J.; Langmuir 2008, $24,5233$.

52. Jeon, J.; Uthaman, S.; Lee, J.; Hwang, H.; Kim, G.; Yoo, P. J.; Hammock, B. D.; Kim, C. S.; Park, Y. S.; Park, I. K.; Sens. Actuators, B 2018, 266, 710.

53. Li, X.; Jiang, L.; Zhan, Q.; Qian, J.; He, S.; Colloids Surf., A 2009, 332, 172.

54. Sonuç Karaboğa, M. N.; Şimşek, Ç. S.; Sezgintürk, M. K.; Biosens. Bioelectron. 2016, 84, 22.

55. Khan, M. Z. H.; J. Electron. Mater. 2017, 46, 2254.
56. Brett, A. M. O.; Brett, C. M. A.; Electroquimica: Príncipios, Métodos e Aplicações; Livraria Almedina: Coimbra, Portugal, 1996.

57. Slimi, H.; Barhoumi, A.; Waldhoff, N.; Duponchel, B.; Poupin, C.; Cousin, R.; Leroy, G.; Guermazi, S.; Superlattices Microstruct. 2018, 120, 670.

58. Silva, A. T. B.; Coelho, A. G.; Lopes, L. C. S.; Martins, M. V. A.; Crespilho, F. N.; Merkoçi, A.; da Silva, W. C.; J. Braz. Chem. Soc. 2013, 24, 1237.

59. Mandenius, C. F.; Welin, S.; Danielsson, B.; Lundström, I.; Mosbach, K.; Anal. Biochem. 1984, 137, 106.

60. Ozawa, M.; Ozawa, T.; Nishio, M.; Ueda, K.; J. Mol. Graphics Modell. 2017, 75, 117.

61. Zhang, K.; Liu, G.; Goldys, E. M.; Biosens. Bioelectron. 2018, 102,80 .

62. Sepúlveda, B.; Angelomé, P. C.; Lechuga, L. M.; Liz-Marzán, L. M.; Nano Today 2009, 4, 244.

63. Girotto, E. M.; de Paoli, M.-A.; Quim. Nova 1999, 22, 358.

64. Liu, S. Q.; Ju, H. X.; Anal. Biochem. 2002, 307, 110.

65. Pei, R.; Cheng, Z.; Wang, E.; Yang, X.; Biosens. Bioelectron. 2001, 16, 355.

66. Rajesh; Sharma, V.; Mishra, S. K.; Biradar, A. M.; Mater. Chem. Phys. 2012, 132, 22.

Submitted: April 1, 2020 Published online: November 17, 2020 